\title{
Environmental Racism and Natural Disasters: Preparing for a Future Defined by Climate Change
}

\author{
Patrick Mays ${ }^{1}$, Michael Bischoff ${ }^{\#}$, and Ronald Schmidt\# \\ ${ }^{1}$ North Mecklenburg High School, Huntersville, NC, USA \\ \#Advisor
}

$\underline{\text { ABSTRACT }}$

This paper argues that the negative effects of climate change induced natural disasters are felt disproportionately by poor and minority communities, and that it is more difficult for them to recover after crises. Because climate change has resulted in an increase in the frequency and severity of natural disasters and is only expected to get worse, disparate effects from natural disasters are a crucial topic to focus research on. This paper will expand the framework for future research in the field of environmental justice by establishing a focus on the intersection between global warming, natural disasters, and environmental racism. It will also illustrate the disparate impact of natural disasters on poor and minority communities with a series of case studies and will evaluate the government's response in each case.

\section{Introduction}

Natural disasters continue to have a devastating impact on the lives of many people, so nuanced research focused on understanding their impacts is critical to improve policies aimed at mitigating them. Specifically, environmental justice research about how natural disasters have disparate effects on poor and minority groups is crucial to proper understanding of the crisis, and thus, effective policymaking. Post-racialist plans or plans based in false universalism are formed with a lack of understanding of the disparities that cause poor and minority communities to suffer more due to natural disasters. As a result, they will inevitably fail to support those communities, as they do not account for the factors that put them in more danger in the first place (powell, 2015). If policymaking focus is not put on the groups most susceptible to this crisis, the outcomes can be devastating, resulting in unnecessary death and suffering on a massive scale.

\section{Literature Review}

The environmental justice movement has historically focused on the disparate effects of human created environmental harms such as landfills, particulate matter in the air, power plants, and so on, because those were the most obvious examples of intentionally human-designed crises (see, e.g., Godsil, 1991, Bullard, 1993, Bullard, 1999, Pulido, 2000). While these are important issues to research, the environmental justice issue of climate change and natural disasters is a crisis that is especially important to focus on. With global warming, natural disasters are getting worse, and the crisis is only going to escalate as time goes on, meaning it is particularly important to plan and research effective solutions now, so they can be implemented before the crisis gets worse. Although fewer aspects of these disasters may be directly human caused, it is important to understand the shortcomings of the current system to avoid disparate impact and unnecessary suffering. Only a few natural disasters have been rigorously framed through the lens of environmental racism, for example the wealth of literature on Hurricane Katrina that can be found in most bibliographic search engines (see, e.g., Henkel et al., 2006, Tomlinson, 2006, Green et al., 2013, Cutter, 2006, Karaye et al., 2019, Bullard, 2008). However, many others such as the Texas power outages or Hurricane Harvey are not represented 
nearly as much in the literature despite data showing that both of these crises had a significant disparate impact (e.g., Chakraborty et al., 2019, Najmabadi, 2021).

There needs to be a greater focus in the literature on specifically mitigating the disparate effects of natural disasters, as opposed to focusing the analysis on the origins of inequality in the US and applying the resulting theory of power to natural disasters. To clarify, analysis about how inequality formed in the US is extremely important, but research on the mitigation of natural disasters from an environmental justice perspective would be a valuable and fresh angle with which to approach inequality and environmental justice. Climate change is an urgent problem, and there is not time to solely analyze broader origins and structures of inequality without a robust analysis of how to mitigate its harmful manifestations in the context of natural disasters. Eliminating structures that perpetuate discrimination in the United States is a long process that will take a great amount of theorizing and effort to put into practice, and in the meantime, failure to adopt policies to mitigate the impact of natural disasters will cause disadvantaged people to suffer even more. Even if mitigatory policies do not resolve the root of the problem, they will still improve the lives of many. Additionally, knowledge is always contextual, so in-depth analysis of how natural disasters disparately affect different groups is a critical piece of research to flesh out if one plans to integrate the impacts of natural disasters into a broader theory of power. Specifically, understanding how the crisis manifests itself, i.e., what impacts natural disasters have on poor and minority groups is important to understanding is a critical piece of information to any historical analysis, which makes this subject doubly important to research.

\section{Methods}

To find the best existing literature on each question analyzed in this paper, several bibliographic search engines were used: JSTOR, ProQuest, and ResearchGate, along with articles from many other journals. From there, articles were chosen for inclusion and citation based on their rigor and focus on the topic of natural disasters viewed through an environmental racism frame. Articles which presented not only data, but also interpretation were preferred, as analysis of possible causal factors of disparate impact are very important to consider for possible real-world applications of crisis prevention, and to establish a strong, direct link between natural disasters and disparate impacts. This analysis did not focus on theories of power or broader analysis on the origins of inequality in the United States, but rather looked at more specific case studies and analyzed the possible causal factors, including structural and systemic ones.

\section{Results}

To illustrate how this environmental racism frame can be used to understand the impacts of natural disasters, this paper will analyze several case studies. First, it will analyze Hurricane Katrina and Hurricane Harvey. There will be a review of both the underlying conditions and the insufficient government response that created a crisis for poor and minority communities in both disasters. Next, it will analyze the disparate impacts of the COVID-19 pandemic with a focus on the specific factors that exposed minority communities the most, underscoring the need for greater aid. Finally, it will analyze the impacts of the recent power grid issues in Texas on poor and minority communities.

\section{The Disparate Impacts of Hurricane Katrina}

Hurricanes are an extremely common type of natural disaster, which makes them key to understand for the broader field of disaster prevention. This is especially important, as climate change is going to make the impacts of hurricanes much more dangerous. Although it is not clear whether global warming increases the frequency of hurricanes, most scientific evidence, including studies from NASA, find that global warming will significantly increase the severity of hurricanes (Buis, 2020). Hurricane Katrina is an example of the devastating impact which powerful hurricanes can have. When Katrina hit in 2005, coastal cities were devastated by a massive storm surge. When it passed by New 
Orleans, the levee system that contained the water from Lake Pontchartrain was overwhelmed by the massive quantity of rainfall generated by the storm surge, flooding huge portions of the city. Hurricane Katrina is certainly the most often referenced example of environmental racism from a natural disaster. There is a mountain of literature around the disparate impacts of Katrina across racial and socio-economic lines, for example the disparate impact on black communities that were uninsured against floods (Henkel et al., 2006). Race and class were correlated with the chance of dying from the effects of Hurricane Katrina, and 62\% of the dead in New Orleans were African American (Tomlinson, 2006). These harms were the result of a multitude of factors. However, for the sake of simplicity two major sources of disparate impact will be covered: disaster susceptibility and the effectiveness of the government's response.

Poor and minority neighborhoods are more likely to be in disaster-susceptible areas, and thus are likely to sustain more damage. Neighborhoods safer from natural disasters are in more expensive, gated communities where barriers to entry such as cost and racism prevent poor and minority groups from moving in (Green et al., 2013). Some studies map the effects of hurricane Katrina against the social vulnerability of neighborhoods (evaluated using factors such as safety of infrastructure, political capital, etc.) and find that more socially vulnerable communities were more significantly affected by Katrina (Cutter, 2006). Factors such as cost also inhibit poorer groups' ability to recover effectively from natural disasters, which creates a much more devastating long-term effect on these groups (Cutter, 2006). This leads to the conclusion that profit margins are driving poor and minority people into the line of fire, while shielding wealthier people who could better weather the costs associated with more disaster-prone areas and who would more than likely have the political capital necessary to attract security measures against those disasters. Not only did poor and minority groups tend to live in areas that were disproportionately affected by Katrina, but studies find that they also had less ability to evacuate due to lack of transportation - and this is where significant government response should have been at the time - in aiding the evacuation of vulnerable neighborhoods. A survey of residents who did not evacuate during Katrina found that 55\% did not evacuate due to lack of transportation, and in addition, people with pre-existing medical conditions or minority status were less likely to evacuate (Karaye et al., 2019). This is a clear indicator that the government's response was not sufficient to overcome barriers inherent in the evacuation process. The impact of this was an increase in the likelihood of drownings, which was the leading cause of death due to Hurricane Katrina (Karaye et al., 2019). Another major component of the government response to any natural disaster is of course the post-disaster recovery effort. The fact that poor and minority citizens were disproportionately impacted by Katrina would logically justify an increased government effort to aid those groups after the crisis. Despite this however, prominent figures in the literature conclude that government responses, particularly in waste cleanup were biased towards white communities (Bullard, 2008). This creates an interlocking system where the most vulnerable communities are the most exposed to natural disasters, the least equipped to effectively respond to them, and do not receive adequate government support to make up for either of these factors, almost ensuring that they take the brunt of the impact.

\section{The Disparate Impacts of Hurricane Harvey}

When Hurricane Harvey smashed into southeastern Texas in 2017 it was a Category 4 storm with winds of 130 miles per hour. It devastated the areas it hit, causing 40-61 inches of rainfall. The ensuing floods damaged property, killed many, and destroyed lives. Despite its severe impact, Hurricane Harvey was not covered in environmental justice literature nearly as extensively as Katrina. The decline in attention from the academic community, however, does not mean the impact of Harvey was any less devastating for poor and minority communities. Despite happening more than a decade after Katrina, many of the same disparities in impact and deficiencies in response were present. This is a major red flag for the effectiveness of the federal and state governmental response. Even though Katrina was one of the most well documented instances of a natural disaster causing disparate impact, Harvey had many of the same impacts years later. Unsurprisingly, poor and minority individuals and communities were much more susceptible to damages from Hurricane Harvey. Studies find that both negative socioeconomic status and minority status were significantly correlated with greater extent of flooding, and that majority white areas experienced significantly less 
flooding (Chakraborty et al., 2019). Other studies have similarly found that poor and minority areas in Texas were the most vulnerable to natural disasters and had less ability to evade the most severe impacts of natural disasters.

As in the case of Hurricane Katrina, lack of transportation or options for evacuation compounded the impact of these crises for poor and minority groups and put them directly into the line of fire. Notably, analyses have also found that disabilities or poor physical and mental health limited evacuation options for many people due to concerns about access to effective medical care. This, of course, inhibits access to basic necessities. Not only do factors like flooding and heavy winds seriously restrict communities' ability to resupply themselves, but the limited transportation options which restricted these communities' ability to evacuate in the first place also makes navigating storm-torn environments extremely difficult. Even if these people were able to reach a store that was still open and had the resources they needed, the price spikes due to disaster conditions were hardly accommodating for poorer groups (Karaye et al., 2019, Ramer, 2017). In addition to this, robust studies have determined that the most socially vulnerable areas (communities with poor, minority, or disabled residents) also had significant deficiencies in shelter capacity (Karaye et al., 2019). This was most likely due to an underestimation of the resources necessary to effectively make up for both the disparity in disaster vulnerability and the lack of capacity to independently evacuate from natural disasters, as well as a general disregard for poor and minority communities by policymakers. Studies which have mapped the amount of government aid a community received over that community's minority status find that minority communities receive significantly less aid overall. This illustrates the self-reinforcing nature of these systemic problems; the communities that need the most aid do not have the political or economic influence to draw in the aid that they need, and are also the most discriminated against, which only puts them into a worse position (Karaye et al., 2019, Ramer, 2017). This creates a paradox: how, without significant government support, are poor and minority groups that are more likely to live in an area vulnerable to disasters, less likely to have the transportation necessary to evacuate, and more likely to lack the monetary resources necessary to effectively recover after the storm supposed to cope with these disasters? This problem is self-reinforcing: if the communities that are already the least able to recover are the most vulnerable and do not receive sufficient government assistance, they will be in an even worse position than before; even less prepared to weather the next storm. Despite this, the disasters will come, unrelenting, as global warming brings with it more and more dangerous storms.

\section{The Disparate Impacts of the COVID-19 Pandemic}

Although the COVID-19 pandemic might not be the first thing that comes to mind when one thinks about natural disasters, diseases are just as much a naturally occurring threat as anything else, and terrifyingly, they too have been getting worse with climate change. Warming temperatures are projected to increase the number of infectious disease outbreaks, which could generate even more insecurity for at-risk communities (see, e.g., Kurane, 2010, Jordan, 2019, World Health Organization, n.d.). Diseases also have a massive disparate impact on poor and minority communities, and COVID-19 exemplifies this. Minority groups are multiple times as likely to be infected, hospitalized or killed by COVID-19 (CDC, 2021, Tai et al., 2021). This is only compounded by barriers to healthcare and insurance for poor and minority communities such as inadequate infrastructure, poverty, or lack of access to quality care options in the area. This not only directly impacts the ability to gain access to treatment for COVID-19, but also increases the likelihood that underlying health conditions go untreated, which makes the impacts of COVID-19 much more severe (Tai et al., 2021, Yancy, 2020, Garcia et al., 2020). Worse living conditions in poor and minority communities due to structural racism underlies this problem. Poor and minority communities not only tend to have less access to reliable and effective healthcare and transportation infrastructure, but also tend to have high density housing, multi-generational housing (which puts older groups at greater risk), housing insecurity (especially because of bad development practices like gentrification), lack of access to healthy foods, and in some cases even water scarcity, all of which compound the risk of COVID-19 infection or worsen its impacts (Tai et al., 2021, Yancy, 2020, Garcia et al., 2020). This problem is also self-reinforcing. When your job requires you to be in person, you need access to public transportation to get there, you do not have enough in savings to miss even a few days of work, and you do not have a high 
enough position in your company to have access to benefits such as paid sick leave; your economic position will become even more dire. Once that happens, you will have even less ability to afford and access the care you need, checkups to ensure you are healthy, or maintenance for a pre-existing condition (Tai et al., 2021, Buheji et al., 2020).

The situation surrounding the government response to this pandemic has been complex and inconsistent. The sheer length of time in which the number of COVID-19 cases, hospitalizations, and deaths grew dramatically is, however, extremely frightening, and shows how maintaining strong public health infrastructure and supporting poor and minority groups who bear a greater risk is critical to avoid another disaster like this in the future.

\section{The Disparate Impacts of the Texas Power Outages}

Although intuitively it would seem that the increase in temperature from global warming might decrease the number of cold snaps, the opposite effect will likely occur, as global warming is predicted to cause a significant increase in extreme weather swings (Robbins, 2019). The recent power outages in Texas exemplify how even a single extreme weather event can be disastrous if it is unexpected for a particular climate region. The recent Texas cold snap caused a major crisis with the electrical grid when energy demand spiked after communities across the state cranked their heaters up to combat the freezing temperatures. In addition to this, frozen energy infrastructure caused by the cold weather resulted in blackouts and insufficient energy to meet demands (Chang, 2021, Domonoske, 2021). This disaster too, harmed poor and minority communities disproportionately. When energy prices spiked due to the energy shortage, many could not pay, and were left with few options. Communities then had to resort to emergency measures to keep warm and nourished. However, poor and minority communities were more restricted in their ability to stock up on resources for a disaster like this beforehand due to structural factors keeping them in poverty. This resulted in desperate struggles to find basic necessities for these communities, and many had to resort to third party food distribution methods such as the Austin Justice Coalition (Yancey-Bragg and Jervis, 2021, Dobbins and Tabuchi, 2021, Gonzalez, 2021). Problems generated by racism again underpinned the crisis. One of the most important factors was the quality of infrastructure. Historical and contemporary structural and institutional factors like disproportionate poverty rates in minority communities, redlining, blockbusting, gentrification, and other issues all shoehorned minority groups into neighborhoods with poor infrastructure. These communities were therefore much less equipped to weather this disaster. Houses lacked effective insulation, backup power, and were usually not designed by an architect in such a way that they could maximize energy efficiency or preserve heat on their own (Yancey-Bragg and Jervis, 2021, Dobbins and Tabuchi, 2021). Poor and minority communities again have the most difficulty recovering from a crisis like this without significant government aid, as they were already structurally and institutionally disadvantaged before they were hit with the brunt of the impact of the cold snap. When power bills in the thousands of dollars come rolling in, poor and minority communities are the most affected. Then there is the physical property damage generated by freezing temperatures, which represents an extremely significant cost for poor and minority communities with less resilient infrastructure (Najmabadi, 2021, Gonzalez, 2021, Hernández, 2021). This illustrates the disparate impact of even seemingly small natural disasters - a simple cold snap caused a state-wide crisis which is having lasting impacts on poor and minority communities.

\section{Conclusion and Implications}

Examining the disparate impacts of natural disasters through the lens of environmental racism should be a crucial objective in future policymaking and scholarship. Understanding the ways in which the impacts of a natural disaster can be distributed unequally is critical to understanding how to effectively mitigate these unequal harms and support vulnerable communities. This research can guide policymakers away from post-racialist or false-universalist policies which do not give the necessary weight to communities that are hit the hardest by natural disasters, or worse directly racist policies which distribute more aid to wealthy and white communities who tend to need it the least. The case 
studies examined here, although they only analyze the disasters at a basic level, illustrate how natural disasters can severely impact poor and minority communities and show that even seemingly very different crises can all have similar effects on the disenfranchised in society, punctuating the need for effective policy response.

\section{Future Research}

This field is in desperate need of more research to guide policymakers. The Trump administration made significant rollbacks of climate protections and failed to pass significant legislation to prevent carbon emissions (Krebs, 2018). Even if the Biden administration begins to reverse certain climate policies, society will still be severely impacted by climate change. Because there has been a lack of policy addressing this issue for the past four years, a shift to renewable energy must be accompanied by robust policies that mitigate the impact of natural disasters, or else we risk massive amounts of suffering. The need for more robust analysis in the literature can be illustrated by comparing the body of literature on disaster mitigation to that of climate change prevention. There is a mountain of literature on methods of climate change prevention, such as renewable energy, carbon capture, etc., however, there is comparatively little literature focusing on the mitigation of natural disasters caused by climate change. This presents a problem. Although the academic community has put forward many robust plans for climate change prevention, the policymaking community has not implemented them consistently or quickly, therefore exacerbating climate change and increasing the need for disaster mitigation techniques, which is where the literature is weaker. Therefore, future research should analyze specific factors that contribute to these issues, and when possible, recommend policy solutions to these problems.

Future research should also include analytic models that synthesize and review a multitude of different instances of natural disasters having disparate effects. Individual analyses of crises are important, but broader analyses can reveal trends or issues that continue to be prevalent through multiple crises, and additionally, this method of analysis can be more effective in convincing policymakers of the scope of the problem and can therefore be more likely to create important change.

\section{Limitations}

At the time this paper was written, the crisis with the Texas power outages was still ongoing. As a result, there were no rigorous sociological analyses published on the issue, and most of the data shown in this paper was the best available information reported soon after the crisis. Therefore, future research should continue to analyze this crisis in more depth and more rigorously review possible causal factors.

Additionally, this paper does not provide in-depth policy recommendations, as it does not focus on a specific crisis or analyze enough case studies to rigorously illustrate common causes of disparate effects. Future research should work towards illustrating these trends so that preventative policies can be put in place to counteract these problems.

\section{Acknowledgements}

I would like to thank Mr. Michael Bischoff and my Grandfather for all of their help and advice throughout this process.

\section{References}

Buis, Alan. (2020, March 10). How Climate Change May Be Impacting Storms Over 
Earth's Tropical Oceans. NASA, https://climate.nasa.gov/blog/2956/how-climate-change-may-beimpacting-storms-over-earths-tropical-oceans/.

Bullard, Robert D. (2008). Differential vulnerabilities: Environmental and economic inequality and government response to unnatural disasters. Social Research, 75(3), 753-7 84,1033. Retrieved from http://nclive.org/cgi-bin/nclsm?url=http://search.proquest.com/scholarly-journals/differentialvulnerabilities-environmental/docview/920744459/se-2?accountid=13217.

Bullard, Robert D. (1999) Dismantling Environmental Racism in the USA, Local Environment, 4:1, 5-19, DOI: 10.1080/13549839908725577.

Bullard, Robert D. (1993). Confronting Environmental Racism: Voices from the Grassroots. United States: South End Press.

Buheji, Mohamed \& Cunha, Katiane \& Mavrić, Bartola. (2020). The Extent of COVID-19 Pandemic Socio-Economic Impact on Global Poverty. A Global Integrative Multidisciplinary Review. American Journal of Economics. 10. 213-224. 10.5923/j.economics.20201004.02.

Centers for Disease Control and Prevention (CDC), (2021, Feb. 18). Risk for COVID-19 Infection, Hospitalization, and Death By Race/Ethnicity, https://www.cdc.gov/coronavirus/2019-ncov/covid-data/investigations-discovery/hospitalization-death-byrace-ethnicity.html.

Chakraborty, J., PhD., Collins, T. W., PhD., \& Grineski, S. E., PhD. (2019). Exploring the Environmental Justice Implications of Hurricane Harvey Flooding in Greater Houston, Texas. American Journal of Public Health, 109(2), 244-250. doi:http://dx.doi.org/10.2105/AJPH.2018.304846.

Chang, Alvin. (2021, Feb. 20). Why the cold weather caused huge Texas blackouts - a visual explainer. The Guardian, https:/www.theguardian.com/us-news/2021/feb/20/texas-power-gridexplainer-winter-weather.

Cutter, S. L., Emrich, C. T., Mitchell, J. T., Boruff, B. J., \& al, e. (2006). The Long Road Home: Race, Class, and Recovery from Hurricane Katrina. Environment, 48(2), 8-20,2. Retrieved from http://nclive.org/cgi-bin/nclsm?url=http://search.proquest.com/scholarly-journals/long-road-home-raceclass-recovery-hurricane/docview/224015968/se-2 accountid=13217 .

Dobbins, James and Tabuchi, Hiroko. (2021, Feb. 16). Texas Blackouts Hit Minority Neighborhoods Especially Hard. New York Times, https://www.nytimes.com/2021/02/16/climate/texasblackout-storm-minorities.html.

Domonoske, Camila. (2021, Feb. 18). No, The Blackouts in Texas Weren't Caused By Renewables. Here's What Really Happened. NPR, https://www.npr.org/sections/live-updates-winterstorms-2021/2021/02/18/968967137/no-the-blackouts-in-texas-werent-caused-by-renewables-heres-whatreally-happened.

Garcia, Marc A, PhD \& Homan, Patricia A, PhD \& García, Catherine, PhD \& Brown, Tyson 
H, PhD. (2020). The Color of COVID-19: Structural Racism and the Disproportionate Impact of the Pandemic on Older Black and Latinx Adults, The Journals of Gerontology: Series B, Volume 76, Issue 3, March 2021, Pages e75-e80, https://doi.org/10.1093/geronb/gbaa114.

Godsil, R. (1991). Remedying Environmental Racism. Michigan Law Review, 90(2), 394427. doi:10.2307/1289559.

Gonzalez, Oriana. (2021 Feb. 17). Texas power outage highlights inequalities for minority neighborhoods. AXIOS, https://www.axios.com/texas-power-outage-minority-neighborhoodsinequality-f57e3e24-a137-4705-ba5f-222f545bca0e.html.

Green, R. D., Kouassi, M., \& Mambo, B. (2013). Housing, race, and recovery from hurricane Katrina. Review of Black Political Economy, 40(2), 145-163. doi:http://dx.doi.org/10.1007/s12114-011-9116-0.

Henkel, Kristin \& Dovidio, John \& Gaertner, Samuel. (2006). Institutional Discrimination, Individual Racism, and Hurricane Katrina. Analyses of Social Issues and Public Policy. 6. 99 - 124. 10.1111/j.1530-2415.2006.00106.

Hernández, Arelis R. (2021, Feb. 28). The power is back, but millions of Texans wonder what it will take to fully recover - and who will help them. The Washington Post, https://www.washingtonpost.com/national/texas-recovers-winter-storm-damage/2021/02/28/37df98187846-11eb-948d-19472e683521_story.html.

Jordan, Rob. (2019, Mar. 15). How does climate change affect disease? Stanford Earth, https://earth.stanford.edu/news/how-does-climate-change-affect-disease.

Karaye I.M., Thompson C., Horney J.A. (2019). Evacuation Shelter Deficits for Socially Vulnerable Texas Residents During Hurricane Harvey. Health Services Research and Managerial Epidemiology. doi:10.1177/2333392819848885.

Krebs, C. (2018). The Trump Administration's Hasty Environmental Rollbacks. Texas Environmental Law Journal, 48(2), 313-354. https://heinonline.org/HOL/Page? collection=journals\&handle=hein.journals/txenvlw48\&id=332\&men_tab=srchresults\#.

Kurane I. (2010). The effect of global warming on infectious diseases. Osong public health and research perspectives, 1(1), 4-9. https://doi.org/10.1016/j.phrp.2010.12.004

Pulido, Laura (2000). Rethinking Environmental Racism: White Privilege and Urban Development in Southern California, Annals of the Association of American Geographers, 90:1, 12-40, DOI: 10.1111/0004-5608.00182

Najmabadi, Shannon (2021, Feb. 22). Texans blindsided by massive electric bills await details of Gov. Greg Abbott's promised relief. The Texas Tribune, https://www.texastribune.org/2021/02/22/texas-pauses-electric-bills/.

powell, john a. 2015. Racing to Justice: Transforming Our Conceptions of Self and Other 
to Build an Exclusive Society. Bloomington: Indiana University Press.

Ramer, A. (2017, Sep 13). Environmental racism: Hurricane Harvey Falls Hardest on LowSES, Marginalized Communities. University Wire. Retrieved from http://nclive.org/cgi-bin/nclsm?url=http://search.proquest.com/wire-feeds/environmental-racism-hurricaneharvey-falls/docview/1938214393/se-2?accountid=13217.

Robbins, Jim. (2019, Nov. 14). Climate Whiplash: Wild Swings in Extreme Weather Are on the Rise. Yale, https://e360.yale.edu/features/climate-whiplash-wild-swings-in-extreme-weather-are-onthe-rise.

Tomlinson, Sherrie Armstrong. (2006). No New Orleanians Left Behind: An Examination of The Disparate Impact of Hurricane Katrina on Minorities. Connecticut Law Review, vol.38, no. 5, July, p. 1153-1188. Hein Online.

Tai, Don Bambino Geno \& Shah, Aditya \& Doubeni, Chyke A. \& Sia, Irene G. \& Wieland, Mark L. (2021, Feb. 15). The Disproportionate Impact of COVID-19 on Racial and Ethnic Minorities in the United States, Clinical Infectious Diseases, Volume 72, Issue 4, Pages 703-706, https://doi.org/10.1093/cid/ciaa815.

World Health Organization (WHO). n.d. Climate Change And Infectious Diseases, https://www.who.int/globalchange/climate/en/chapter6.pdf

Yancy CW. (2020). COVID-19 and African Americans. JAMA. 323(19):1891-1892. doi:10.1001/jama.2020.6548.

Yancey-Bragg, N'dea and Jervis, Rick. (2021 Feb. 20). Texas' winter storm could make life worse for Black and Latino families hit hard by power outages. USA Today, https://www.usatoday.com/story/news/nation/2021/02/20/texas-ice-storm-blackouts-minorities-hardest-hitrecovery/4507638001/. 